\title{
NEW BORON AND SILICON FREE SINGLE CRYSTAL-DIFFUSION BRAZING ALLOYS
}

\author{
M. K. Dinkel ${ }^{1}$, P. Heinz ${ }^{2}$, F. Pyczak ${ }^{1 \ddagger}$, A. Volek ${ }^{2 *}$, M. Ott $^{3}$, E. Affeldt ${ }^{4}$, A. Vossberg ${ }^{5}$, M. Göken ${ }^{1}$, R.F. Singer ${ }^{2}$ \\ ${ }^{1}$ Department of Materials Science and Engineering, Institute I \\ ${ }^{2}$ Department of Materials Science and Engineering, Institute II \\ University of Erlangen - Nürnberg, \\ Martensstr. 5, D-91058 Erlangen Germany \\ ${ }^{3}$ Siemens AG Power Generation, Mellinghofer Strasse 55, D-45473 Mülheim \\ ${ }^{4}$ MTU Aero Engines GmbH, Dachauer Str. 665, D-80995 München \\ ${ }^{5}$ MTU Maintenance Hannover GmbH, Münchner Strasse 31, D-30855 Langenhagen \\ *now at Diehl Stiftung \&Co. KG, Stephanstrasse 49, D-90478 Nürnberg \\ *now at Institute for Materials Research, GKSS Research Centre Geesthacht, \\ D-21502 Geesthacht
}

Keywords: Repair, Diffusion Brazing, Single Crystalline, Transient Liquid Phase Bonding,

\begin{abstract}
New diffusion brazing alloys for single crystalline component repair processes were developed and tested. Germanium was used as the melting point depressing element in these binary brazing alloys with germanium contents between 20 to 23 wt.\%. Microstructural analysis has shown that the formation of a single crystalline joint was achieved after extended brazing cycles with these brazing alloys. No secondary phases other than the desired $\gamma^{\prime}$ precipitates were detected within the brazing zone. This result was shown for two parent materials, PWA 1483 and René N5, a first and a second generation superalloy, respectively.

The solidification mechanisms and kinetics were examined and show rather distinct deviations from Transient Liquid Phase Bonding theory for binary systems due to the multicomponent diffusion in the present system. Mechanical testing was performed at room temperature via nanoindentation and at elevated temperatures by hot tensile tests. The nanoindentation results show minor differences in hardness and elastic modulus between brazing joints and parent material. Ultimate tensile strengths of more than $90 \%$ compared to the parent material were obtained in tensile testing at $980{ }^{\circ} \mathrm{C}$.
\end{abstract}

\section{Introduction}

Single crystalline (SX) vanes and blades made of nickel-base superalloys are in service in both industrial gas and aero engine turbines. Due to the improved creep properties of these SX parts, they exhibit a higher level of reliability resulting in prolonged cycles until refurbishment compared to conventionally cast or directionally solidified nickel-base superalloy components. Nevertheless, SX turbine components suffer from creep, fatigue and high temperature corrosion due to exposure to high thermal and mechanical loads [1]. In order to reduce life cycle costs, new repair technologies have to be developed especially for SX parts. To preserve the outstanding high temperature capabilities it is mandatory to retain the single crystalline structure during the repair process.

Diffusion brazing is a well established repair technique for high temperature components in both industrial gas turbines and aero engine turbines. In commercial nickel-base braze alloys, boron or silicon are present as melting point depressing elements. The major benefit of boron and silicon are their capability to reduce the melting point and to diffuse rapidly in nickel-base superalloys. Application of such boron and silicon containing brazes for single crystalline repair of SX-components was shown in several studies [2-7]. It was found that single crystal solidification of the braze can be achieved by isothermal solidification during extended brazing cycles. Diffusion of the melting point depressing elements (MPDs) occurs and the resultant gradient of the MPD concentration results in directional and epitaxial solidification, while the nucleation of new grains in front of the solidification front is suppressed. This is also termed Transient Liquid Phase (TLP) bonding in the literature and was first reported for nickelbase superalloys in the 1970's [8]. However, the application of boron and silicon containing brazes causes a problem, as these elements promote the precipitation of undesired brittle phases during the brazing process, due to the very small solubility of boron in superalloys [9].

The objective of this study was to find and select an appropriate melting point depressant, which is suitable to promote $\gamma^{\prime}$ phase formation while the precipitation of brittle phases is suppressed. This newly developed braze alloy was applied in a Transient Liquid Phase bonding process with the aim to produce single crystalline joints. Joints with different combinations of brazing alloy and parent material were characterized in terms of diffusion kinetics, microstructure and mechanical properties. The holding time during the brazing process as well as the process temperature were varied to obtain an understanding of the influence of these parameters on the kinetics and thermodynamics of the brazing process and on the properties of the resulting microstructures. 
$\underline{\text { Alloys }}$

\section{Experimental}

The brazing process has been developed for the nickel-base superalloys PWA 1483 (12.2Cr-9Co-1.9Mo-3.8W-3.6Al-4.1Ti5Ta-0.07C-Ni-Bal) and René N5 (7Cr-7.5Co-1.5Mo-5W-6.2Al6.5Ta-3Re-0.05C-0.15Hf-0.004B-0.01Y-Ni-Bal) (all composition data is given in wt.\%), which are first and second generation alloys, respectively. These alloys exhibit a regular $\gamma / \gamma^{\prime}$ microstructure as shown in Figure 1. The $\gamma^{\prime}$ particles are of cuboidal shape with an edge length of about 350 to $500 \mathrm{~nm}$.

From the phase diagram it is known that the NiGe system [10] forms a $\mathrm{Ll}_{2}$ structured intermetallic $\gamma^{\prime}$-phase which should be beneficial for the mechanical properties of the brazing zone as precipitation hardening is already achieved before significant interdiffusion of $\mathrm{Al}$ from the parent material has taken place. At a composition of $28 \mathrm{wt} . \%$ of germanium this phase is stable up to the melting point. In the literature [10] this phase is also known as $\beta-\mathrm{Ni}_{3} \mathrm{Ge}$, but for simplicity we will subsequently use the term $\gamma^{\prime}$ to describe it.

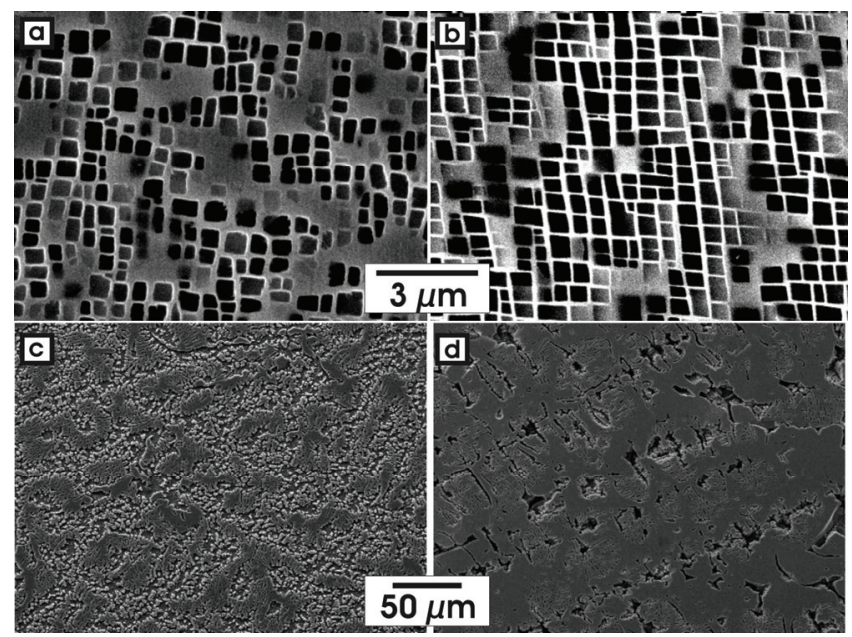

Figure 1: Initial microstructures of a) PWA 1483, b) René N5, c) NiGe20 and d) NiGe23. In pictures a and b the dark phase is the precipitation phase, whereas in the other cases it's vice versa.

Two different binary Ni-Ge brazing alloys (Ni-20wt.\% Ge and Ni$23 \mathrm{wt} . \% \mathrm{Ge}$ ) were electron arc melted on a water chilled copper plate (subsequently termed $\mathrm{NiGe} 20$ and NiGe23). These alloys were subjected to thermal analysis with a differential scanning calorimeter (DSC) Netzsch STA $409 \mathrm{C} / \mathrm{CD}$, to obtain the solidus $\left(T_{s}\right)$ and liquidus $\left(T_{1}\right)$ temperatures, which were determined to be $\mathrm{T}_{\mathrm{s}}=1131{ }^{\circ} \mathrm{C}$ and $\mathrm{T}_{1}=1271{ }^{\circ} \mathrm{C}$ for $\mathrm{NiGe} 20$ and $\mathrm{T}_{\mathrm{s}}=1135{ }^{\circ} \mathrm{C}$ and $\mathrm{T}_{1}=1230^{\circ} \mathrm{C}$ for $\mathrm{NiGe} 23$, see Figure 2 .

As can be seen in Figure $1 \mathrm{c}$ and d, the two brazing alloys exhibit a two phase microstructure consisting of the $\mathrm{L1}_{2}$-structured $\mathrm{Ni}_{3} \mathrm{Ge}$ and the $\gamma$-Nickel matrix. An increase of the $\gamma^{\prime}$-volume fraction with increasing Germanium content can also be observed.

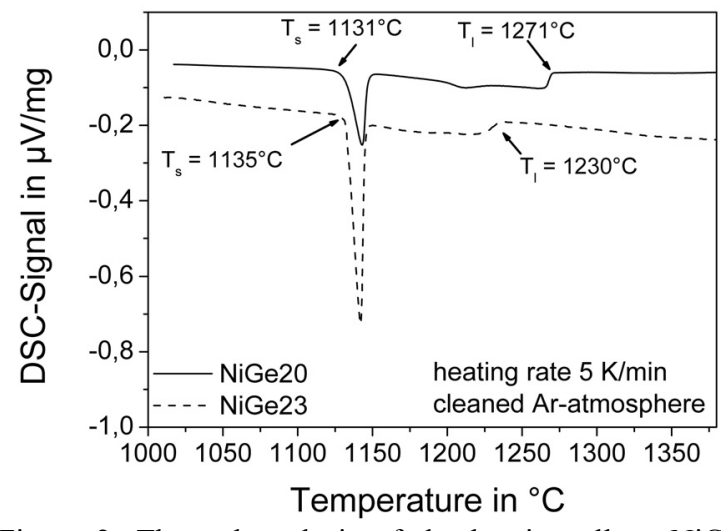

Figure 2: Thermal analysis of the brazing alloys NiGe20 and NiGe23. The solidus temperatures were determined to be 1131 and $1135^{\circ} \mathrm{C}$, the liquidus to be 1271 and $1230^{\circ} \mathrm{C}$.

\section{Characterization}

Microstructural characterization was performed with light (LM) and Scanning Electron Microscopy (SEM). Orientation measurements were made using Electron Back Scattering Diffraction (EBSD) technique [11] with Zeiss 1540 ESB Focused Ion Beam equipped with a Nordlys 2 detector and HKL Channel Six software package. Compositional changes were investigated via Electron Micro Probe Analysis (EPMA) using a Jeol JXA 8100 system.

\section{Brazing Experiments}

First brazing experiments were made with plate shaped specimens with a size $20 \times 13 \mathrm{~mm}^{2}$ and a thickness of $3 \mathrm{~mm}$ for PWA 1483 and $2 \mathrm{~mm}$ for René N5, respectively. Three slits, $7 \mathrm{~mm}$ long and $200 \mu \mathrm{m}$ wide, were spark eroded into each plate. A schematic image of the setup is given in Figure 3.

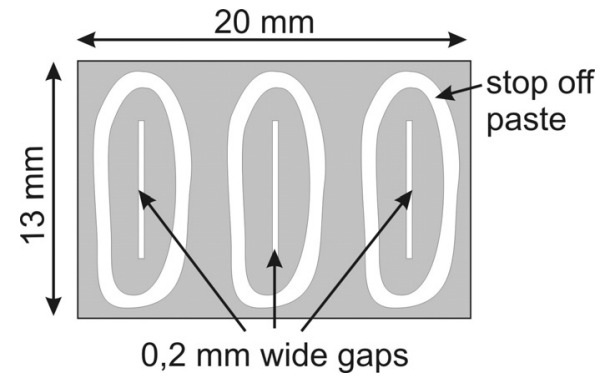

Figure 3: Schematic representation of the brazing sample with 3 slits. The application of the stop-off paste should prevent the liquid from spreading over the whole specimen.

To remove the resulting recast layer and to emulate similar conditions as in the standard industrial process, these samples were Fluoride Ion Cleaned (FIC) at MTU Maintenance $\mathrm{GmbH}$, Hannover. Before braze application, the slits were surrounded by a ceramic stop off paste which kept the liquid brazing alloy in place to ensure adequate feeding into the slit and to prevent the braze from wetting large portions of the specimen surface. This is also common practice in industrial brazing repair processes for superalloy parts. 
Different optimized brazing heat treatments were developed for the two brazing alloys, principally varying in the isothermal brazing temperature. The initial melting of the brazing alloy and filling of the slits was done under vacuum of $3^{*} 10^{-3}$ mbar, the following isothermal heat treatment was performed under an 99.999 pure Ar atmosphere. All experiments were made in a graphite soldering furnace. Because prolonged heat treatments at very high temperature are undesirable from a standpoint of industrial application the exact information about the kinetics of the brazing process is important. Therefore test series with different brazing temperatures and different isothermal dwell times were performed.

Experiments were performed in the temperature range of $1160{ }^{\circ} \mathrm{C}$ to $1230{ }^{\circ} \mathrm{C}$ with holding times of $0.5,12,24$ and $48 \mathrm{~h}$.

The brazed samples were evaluated via light microscopy to assess the degree of gap closure. The remaining liquid fraction (the eutectic zone) could easily be distinguished from the already isothermally solidified area. The isothermally solidified length $\mathrm{x}_{\text {iso }}$ was determined by measuring the remaining eutectic zone in the center of the joint and subtracting it from the initial gap width of $200 \mu \mathrm{m}$ and dividing it by 2 as the situation is symmetric. It should be noted that depending on the process temperature the brazing gap widens in the beginning as the parent material melts back and dilutes the brazing material before isothermal solidification starts. In this case negative values are obtained for the isothermally solidified length in accordance with the definition given above.

\section{$\underline{\text { Mechanical Testing }}$}

To assess the mechanical properties of the brazed joints different testing techniques were applied. In the initial state of process and alloy development mainly nanoindentation experiments were used to get a first impression of the properties. Benefit of this method, besides the high lateral resolution is that the plate shaped specimens could be used, whereas for tensile testing specific samples with larger dimensions had to be utilized.

The high temperature tensile tests were performed to quantify the mechanical properties at temperatures more representative of the service conditions for such parts. Here, information about the strength and also the ductility of brazing joints could be gathered.

\section{$\underline{\text { Nanoindentation }}$}

The nanoindentation measurements shown in this work were performed with a MTS Nanoindenter XP. All measurements were done with a three-sided Berkovich tip. The Berkovich geometry has a tip area function equivalent to the Vickers pyramid. The Berkovich tip was calibrated using fused silica as a reference material and the tip area function was monitored throughout the whole investigation. Also the machine compliance was taken into account.

The positioning of the indentation is controlled with an optical microscope. The machine is equipped with a continuous stiffness module, which applies an additional oscillating force at a frequency of about $45 \mathrm{~Hz}$ to the load during indentation. The contact stiffness is continuously evaluated during loading, and the hardness and reduced modulus were calculated as functions of the indentation depth using the Oliver-Pharr method [12].

It should be mentioned here that the measured Young's modulus results do not represent the elastic anisotropy in the direction parallel to the indentation direction. The results are rather comparable to the modulus of a polycrystalline sample, or a single crystal in a $\langle 110\rangle$ direction $[13,14]$.

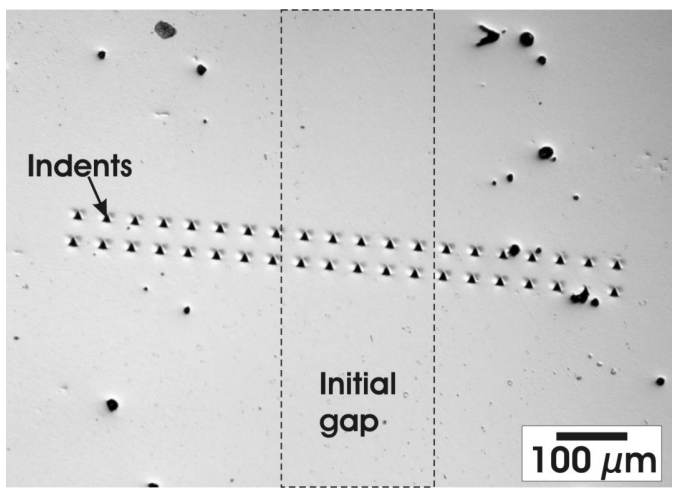

Figure 4: Light optical image of a typical Nanoindentation experiment with a $20 \times 2$ measurement array

\section{Tensile Testing}

In order to monitor the mechanical properties in the range of the service temperature, tensile tests were performed at the temperature of $980^{\circ} \mathrm{C}\left(\sim 1800^{\circ} \mathrm{F}\right)$. Testing was done in a Hegewald\&Peschke Type STE-12-HR-210, equipped with a three zone resistance furnace for specimen heating. Temperature control was performed via Type $\mathrm{S}$ thermocouples. A high temperature extensometer type Maytec PMA 12 /V7-1 with a gauge length of $12 \mathrm{~mm}$ was used for strain measurement. The tests were conducted as constant elongation rate tests (CERT) with an elongation rate of $0.04 \mathrm{~mm} / \mathrm{s}$. For these tests rectangular specimens were used, which were machined by spark erosion. The specimen shape is shown in Figure 5. The tests were performed with full brazing samples, i.e. a brazing joint extended over the complete cross section, perpendicular to the load axis. For comparison, reference samples were tested, which underwent the full brazing thermal heat treatment cycle. All samples were oriented with the load axis close to the $\langle 100\rangle$ direction.

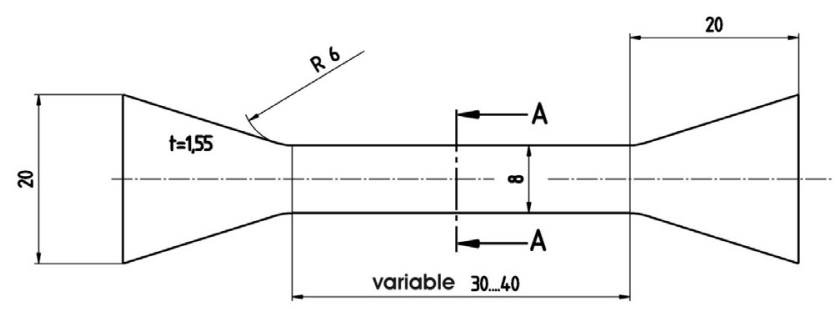

Figure 5: Flat tensile test specimen for hot tensile tests at $980{ }^{\circ} \mathrm{C}$.

\section{Results}

\section{Brazing Kinetics}

The isothermally solidified length $\mathrm{x}_{\text {iso }}$ vs. square root of time $\mathrm{t}^{0.5}$ data for the brazing of PWA 1483 with NiGe23 is shown in Figure 6 . Due to the initial gap width of $200 \mu \mathrm{m}$ the necessary length $\mathrm{x}_{\text {iso }}$ for full isothermal solidification is $100 \mu \mathrm{m}$. Full gap closure is achieved at a temperature $1160{ }^{\circ} \mathrm{C}$. At temperatures 
above $1160{ }^{\circ} \mathrm{C}$, the investigated maximum brazing time is too short to achieve full isothermally gap closure. The sample at $1180{ }^{\circ} \mathrm{C}$ has almost reached the $100 \mu \mathrm{m}$ mark indicating full gap closure, and the samples at higher temperatures are far from attaining the full solidification.

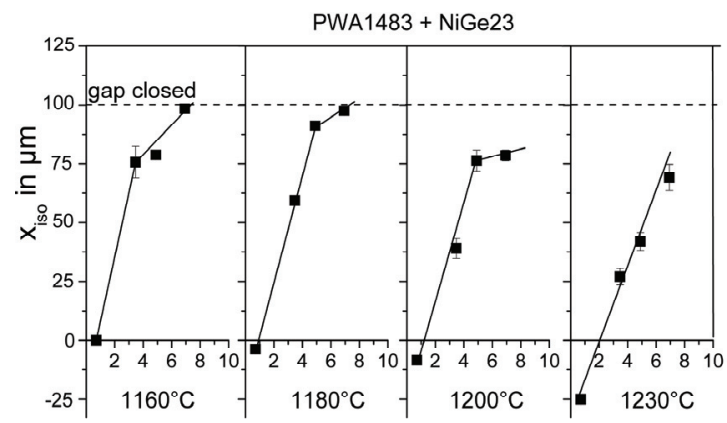

$(\mathrm{t} / \mathrm{h})^{0,5}$

Figure 6: Results of the isothermally solidified length plotted versus the square root of dwell time at different temperatures for the parent material PWA 1483 with NiGe23 braze alloy.

Figure 6 shows that the isothermally closed width at the beginning shifted to negative length values. The shift increases with increasing temperature, reaching a maximum of $-25 \mu \mathrm{m}$ at $1230{ }^{\circ} \mathrm{C}$. This means that the initially liquid layer, i.e. the gap width, widens at $1230{ }^{\circ} \mathrm{C}$ to a thickness of about $250 \mu \mathrm{m}$ because of dissolution of the parent metal, whereas at a temperature of $1160{ }^{\circ} \mathrm{C}$ no widening is observed. Back melting of the parent metal is certainly desirable from a standpoint of cleaning of the gap surface and epitaxial growth, but lengthens the time necessary for isothermal solidification. Back melting is the reason why higher brazing temperatures do not lead to faster gap closure.

Figure 7 shows the results for the brazing of René N5 with NiGe20. At $1160{ }^{\circ} \mathrm{C}$ the braze alloy did not melt sufficiently to fill the gap, therefore no data could be acquired. Similar to the data for PWA 1483 and NiGe23 an increasing widening of the liquid layer with increasing temperature can be seen here with a maximum of about $20 \mu \mathrm{m}$ at $1230{ }^{\circ} \mathrm{C}$. Also for the highest temperature the time necessary for a complete isothermal closure of the gap exceeded the allotted time range in our test series.

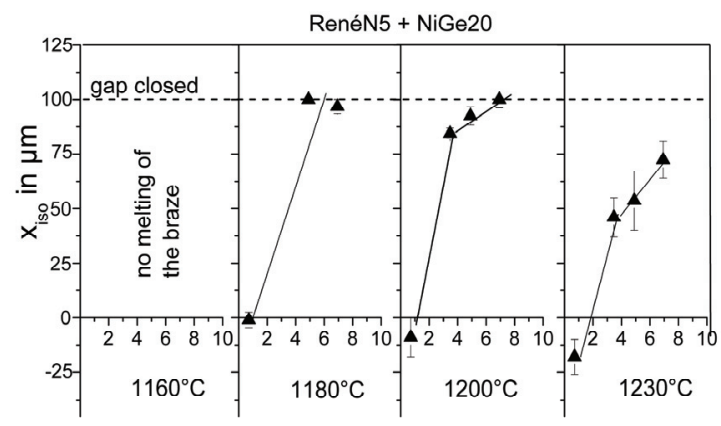

$(\mathrm{t} / \mathrm{h})^{0,5}$

Figure 7: Results of the isothermally solidified length plotted versus the square root of dwell time at different temperatures for parent material René N5 with NiGe20 braze alloy.

Unlike the PWA 1483 braze, here isothermal gap closure is reached at two temperatures, at $1180{ }^{\circ} \mathrm{C}$ after $24 \mathrm{~h}$ and at $1200{ }^{\circ} \mathrm{C}$ after $48 \mathrm{~h}$. However, complete closure might be already reached before $48 \mathrm{~h}$ at $1200{ }^{\circ} \mathrm{C}$, but no data was obtained in between 24 and 48 hours with the plate specimens.

Note that the slope of the curves in Fig. 7 corresponds to the solidification velocity which is controlled by diffusion.

The data implies a change in solidification velocity after some time. This behavior is observed at all temperatures except for $1230{ }^{\circ} \mathrm{C}$ for the PWA 1483 brazing and also at $1180^{\circ} \mathrm{C}$ for the René N5 brazing. An interpretation of this finding will be given later.

\section{Microstructure after brazing}

The microstructure of brazed samples for both parent materials is presented in Figures 8 and 9. Both samples show distinctly different areas within the joint region, which are clearly divided by sharp transitions.

Figure 8 shows the results for brazing of PWA 1483 with NiGe23. The sample was annealed for $48 \mathrm{~h}$ at $1160{ }^{\circ} \mathrm{C}$. The three distinct areas visible in the brazing zone are shown in higher magnification in Figures 8a-c. The whole zone affected by the brazing process (interdiffusion zone + isothermally solidified zone) has a width of about $700 \mu \mathrm{m}$.

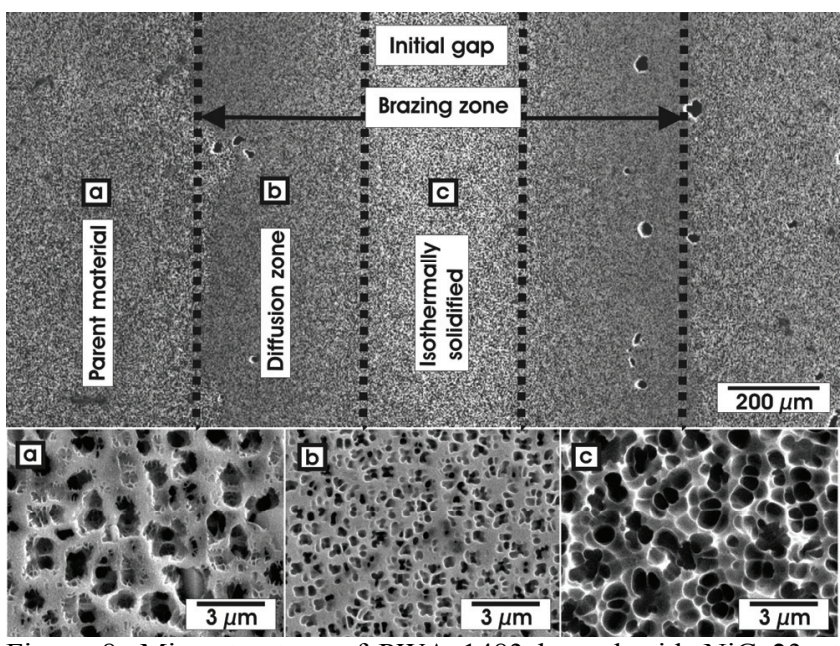

Figure 8: Microstructure of PWA 1483 brazed with NiGe23 at $1160{ }^{\circ} \mathrm{C}$ for $48 \mathrm{~h}$.

As can be expected from the extended heat treatment the microstructure in the base material is strongly affected (Figure $8 \mathrm{a}$ ). The precipitation size and morphology has changed from the desired cuboidal shape with edge length of about $500 \mathrm{~nm}$ to an irregular shape and strongly increased size. The size distribution of the particles seems to be bimodal, with large precipitations in the micrometer range and smaller precipitations in the region of a few hundred nanometers. Adjacent to this area is the diffusion zone which is affected both by the inward diffusion of the alloying elements of the parent material into the former gap, as well as by the outward diffusion of the melting point depressing element, Germanium. This zone features small $\gamma^{\prime}$ precipitates in the size of about $350 \mathrm{~nm}$. The morphology is irregular and partially butterfly-like. In the area of the former gap a third distinct region is observable. Here the size of the precipitate phase is strongly increased compared to the neighboring diffusion zone. The shape of the particles has here changed to spheres. 
The $\gamma^{\prime}$-volume fraction changes over the brazing zone are shown in Figure 10. The base material shows a $\gamma^{\prime}$-volume fraction which is reduced compared to the values reported for PWA 1483 [15] and in the same range as for René N5 prior to the brazing process. In the diffusion zone the volume fraction of the precipitate phase decreases compared to the parent material. The highest volume fraction of the precipitate phase is found in the joint center.

The results of the braze René N5 with NiGe20 differ slightly from the PWA 1483 with NiGe23 sample. Similar to the former, in this case also three different regions are visible. A smaller $400 \mu \mathrm{m}$ wide brazing zone was observed. From the isothermally solidified zone over the diffusion zone to the parent material, the size and the shape of the $\gamma^{\prime}$-precipitates is strongly altered.

Again, in the parent material an increase of the precipitation size is found, but in this case resulted in a more homogenous size distribution with a medium value of about $1 \mu \mathrm{m}$. The microstructure resembles the initial shape, still having almost cubic precipitates although with increased size, Figure 9.

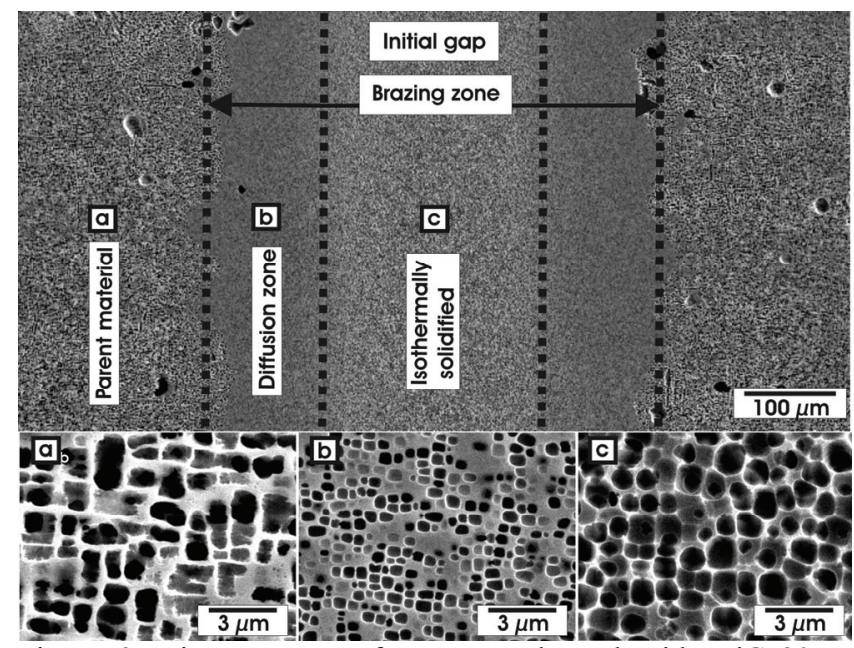

Figure 9 Microstructure of René N5 brazed with NiGe20 at $1200{ }^{\circ} \mathrm{C}$ for $48 \mathrm{~h}$.

In the diffusion zone the $\gamma^{\prime}$ particles are of more cuboidal shape with rounded edges and the size is about $400 \mathrm{~nm}$. The center of the joint, i.e. the isothermally solidified area, shows precipitates of about $1 \mu \mathrm{m}$. Their shape seems to be rather cubic but with strongly rounded edges. In this area the volume fraction of the $\gamma^{\prime}$ precipitates is strongly increased compared to the diffusion zone (see Figure 10), where the minimum volume fraction is observed, and compared to the parent material with its volume fraction in the range of as-received material.

In order to verify the single crystalline solidification of the joint EBSD measurements were performed. EBSD scans were carried out over the whole joint area, including the initial gap as well as the surrounding parent material, see Figure 11. It can be seen that aside from minor scatter, which can be attributed to surface effects, the joints are indeed oriented parallel to the surrounding parent/base material. The orientation results scatter's around $5^{\circ}$.

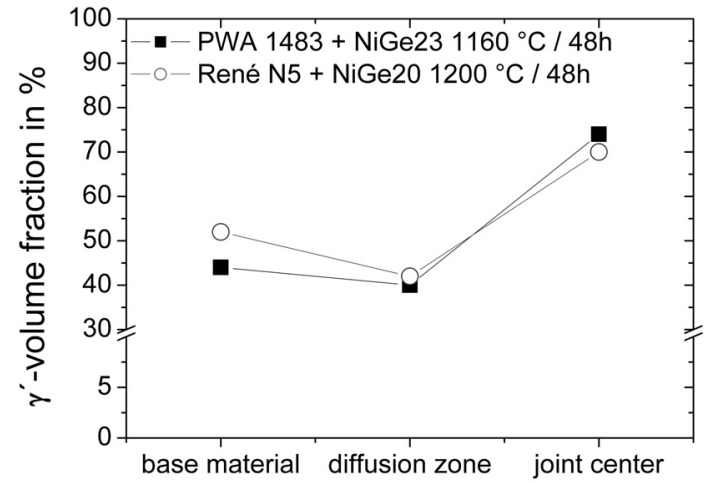

Figure 10: $\gamma^{\prime}$-volume fraction in the joint area. The volume fraction was determined with SEM image analysis

\section{$\underline{\text { Mechanical Properties }}$}

As mentioned previously, nanoindentation measurements were performed during alloy and process development.

Figure 12 show the results for the brazing of PWA 1483 with $\mathrm{NiGe} 23$ for $48 \mathrm{~h}$ at $1160{ }^{\circ} \mathrm{C}$. In the diagram the modulus of elasticity and hardness are plotted. It can be seen that the modulus values in the base material scatter between 220 to $240 \mathrm{GPa}$. In the center of the initial gap a decrease of the modulus to about $200 \mathrm{GPa}$ is visible, although the values in this region exhibit the highest scattering.

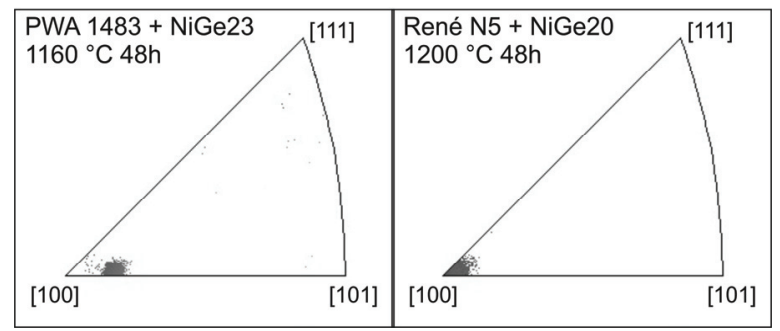

Figure 11: Inverse pole figures of PWA 1483 and René N5 joints.

Within the gap region a hardness decrease of $10 \%$ to $4.2 \mathrm{GPa}$ is found, while the base material reaches a hardness of approximately 4.5 to $4.8 \mathrm{GPa}$.

Figure 13 shows the indentation results for brazing of René N5 with NiGe20 for 48 hours. Here a difference in the modulus and the hardness between the gap area and the base material can clearly be seen. The modulus reaches values of approximately $220 \mathrm{GPa}$, Within the initial gap region the values are reduced to about $205 \mathrm{GPa}$ and also show some transition to the values adjoined.

For the hardness results the effect is even more pronounced. The hardness obtained in the base material region yield around $5 \mathrm{GPa}$ whereas in the initial gap the hardness is reduced by about $10 \%$ to values of $4.5 \mathrm{GPa}$. A rather smooth transition is found in between these two main areas. 


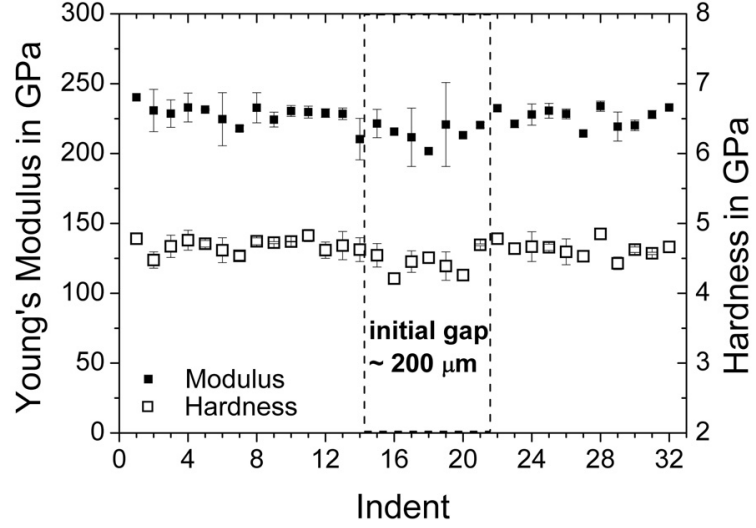

Figure 12: Nanoindentation results of a sample of PWA 1483 with NiGe23 brazed at $1160{ }^{\circ} \mathrm{C}$ for $48 \mathrm{hrs}$. Open symbols denoted hardness, full symbols Young's modulus. The initial gap is indicated with lines.

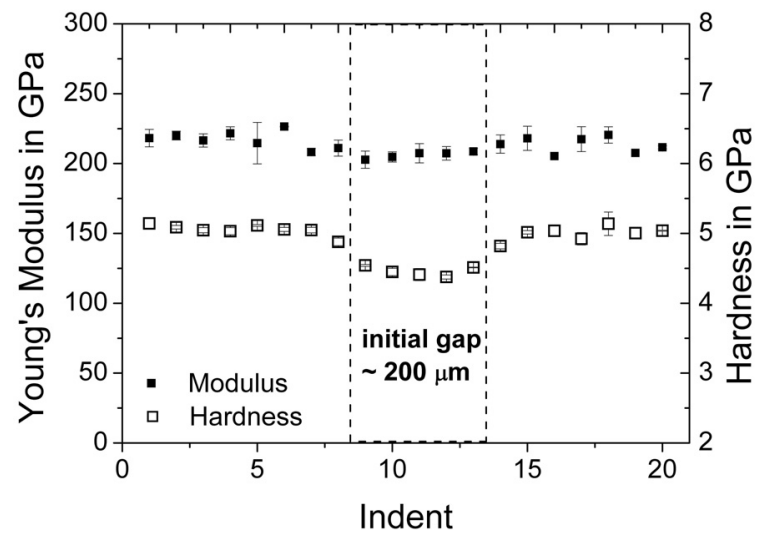

Figure 13 Nanoindentation results of a sample of René N5 with $\mathrm{NiGe} 20$ brazed at $1200^{\circ} \mathrm{C}$ for $48 \mathrm{hrs}$. Open symbols denoted hardness, full symbols Young's modulus. The initial gap is indicated with lines.

\section{$\underline{\text { Tensile Test }}$}

Figure 14 displays the stress strain curves of PWA 1483 with $\mathrm{NiGe} 23$ brazes together with results of a reference sample. These samples were brazed for $55 \mathrm{~h}$ at $1160{ }^{\circ} \mathrm{C}$. The prolonged heat treatment was necessary to account for inaccuracies in the gap preparation, which resulted in variations of gap width between $200 \mu \mathrm{m}$ to $220 \mu \mathrm{m}$. The reference samples received the same heat treatment as the brazed samples. The data was normalized to the UTS of a sample which was given a simulated brazing cycle. This state represents about 85 to $90 \%$ of the UTS of a standard heat treated sample. The strength of PWA 1483 is typical for first generation SC superalloys.

It can be seen that all tested brazed samples reach a strength level of approximately $90-95 \%$ of the reference strength. The reference sample shows a higher rupture elongation than the brazed samples of about $20 \%$. At the test temperature of $980{ }^{\circ} \mathrm{C}$ no distinct strain hardening was found.
The brazed samples rupture with reduced strain to failure, typically $2-3 \%$, but show strong plastic deformation and necking. The elastic regions of the curves show no strong deviation from the reference sample.

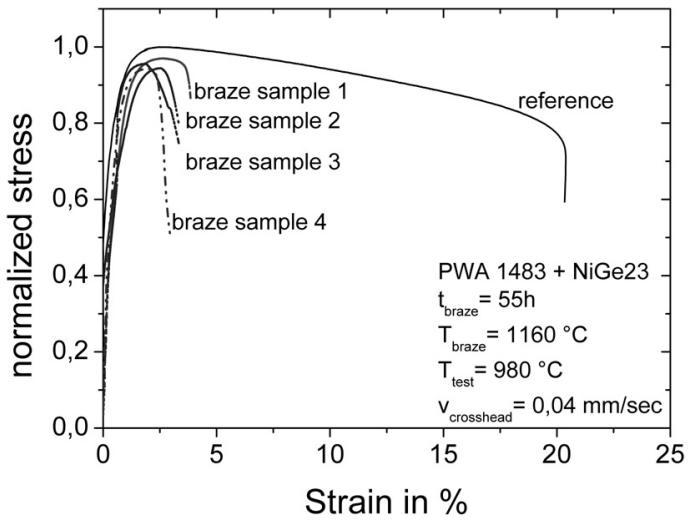

Figure 14: Stress-strain curves for PWA $1483+$ NiGe23 brazing samples. The stress has been normalized to the UTS of the reference sample, which has undergone a simulated brazing cycle.

Figure 15 shows the results of the hot tensile tests at $980{ }^{\circ} \mathrm{C}$ for a series of brazings of René N5 with NiGe20. These tests were performed to quantify the influence of brazing time on the ultimate tensile strength. For ease of comparison the results are normalized with respect to the UTS of the reference samples, which were given a simulated brazing cycle. Again this reference state exhibits about 85 to $90 \%$ strength of the standard heat treated condition. The strength of René N5 is typical for a second generation superalloy. It can be seen that with an increase in dwell time the strength of the brazed specimens approach the strength of the reference material. At a brazing time of 24 hours about $45 \%$ of the reference material strength is achieved. With a slightly longer hold time of $30 \mathrm{~h}$ above $80 \%$ reference strength is obtained and for holding times of $48 \mathrm{~h}$ a value of above $90 \%$ is attained.

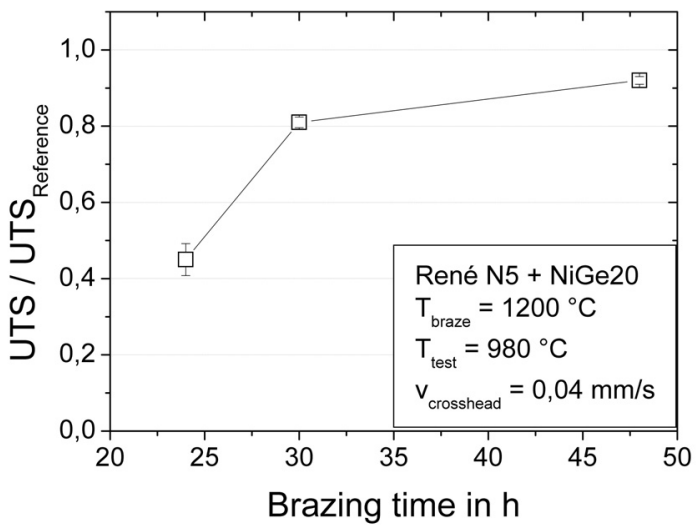

Figure 15: Ultimate tensile strength results for brazes of René N5 with NiGe20 with respect to brazing time. Reference state is condition after a simulated brazing cycle. 


\section{Discussion}

\section{Solidification Kinetics and Mechanisms}

Most treatments on solidification kinetics and mechanisms only deal with transient liquid phase bonding in binary systems [1619].

Basically, the process consists of three stages: The first step consists of melting of the braze, which is accompanied by a dissolution of parent material and a subsequent widening of the liquid layer. This step is considered to be completed within a very short time. The widening becomes more pronounced at higher temperatures, as it is determined by the concentration difference between the initial braze composition and the equilibrium solubility in the liquid phase. From a simple mass balance approach and with the assumption that the liquid density is equal to the solid density $[17,19]$, the widening can be calculated [16]:

$$
W_{\max }=W_{0} \frac{c_{\text {Braze }}}{c_{L \alpha}}
$$

Here $\mathrm{W}_{0}$ is the initial width of the gap, $\mathrm{c}_{\mathrm{Braze}}$ the concentration of the melting point depressing element in the brazing alloy and $\mathrm{c}_{\mathrm{L} \alpha}$ the solubility of the MPD in the liquid phase. $\mathrm{W}_{\max }$ is the end width of the gap after melting back of the parent metal is completed.

In the second step, the isothermal solidification takes place. In the binary case the solidification is solely controlled by the outward diffusion of the melting point depressing element into the parent material. Therefore, the velocity of the solid / liquid interface movement and thus the time to complete closure of the gap depends on the solid state diffusion of the MPD in the base material. Diffusional flux, of course, depends on the diffusivity as well as the solubilities of the MPD in the parent material and in the liquid. Based on Fick's law the motion of the interface can be described as follows:

$$
x_{i s o}=K \cdot \sqrt{D t}
$$

The factor $\mathrm{K}$ depends on the ratio of the MPD solubility in the solid phase $\mathrm{c}_{\alpha \mathrm{L}}$, the solubility in the liquid phase $\mathrm{c}_{\mathrm{L} \alpha}$ and the initial MPD concentration in the base material $\mathrm{c}_{\mathrm{Braze}}[16]$, as follows.

$$
K \cdot e^{K^{2}} \cdot(1+\operatorname{erf}(K) \sqrt{\pi})=\frac{c_{\alpha L}-c_{\text {Braze }}}{c_{L \alpha}-c_{\alpha L}}
$$

In the binary case for a given temperature, $\mathrm{K}$ is constant and the plot of the isothermally closed length versus the square root of time should follow a straight line.

After complete closure of the gap, a homogenization treatment may be applied, which is considered to be the third step in TLP. Due to the fact that we are not applying such a treatment in the present case, we will not discuss this further.

As mentioned before, the model presented above is valid for binary systems. Work on the TLP bonding of superalloys has mainly focused on the microstructural development and not on the theoretical description [20-22], and only little work has been done on the theory of multicomponent Transient Liquid Phase Bonding [23-25].

The predictions of the theory for binary systems can be compared with the experimental results found in this work.

The initial widening of the liquid interlayer, the first stage, can be observed in our multicomponent system, too. This effect can be seen in the Figures 6 and 7, where the isothermally closed length at short times is actually negative, i.e. a widening did occur. The amount of widening also increases with an increase in temperature, which is in good agreement with the theoretical expectation, as the solubility of the MDP in the liquid phase should decrease with increasing temperature leading to more gap widening according to equation (1) [16].

For the second stage two somewhat surprising observations were made:

- For both parent materials investigated an increase in process temperature does not lead to a reduction in the times necessary for isothermal solidification although the diffusion rate must increase with temperature.

- The solidification velocity changes after prolonged heat treatment, i.e. our results do not correspond to equation (2) with a constant $\mathrm{K}$ as discussed above

Based on the activation energies for diffusion an increase in process temperature of about $70 \mathrm{~K}$ should typically triple the diffusivity of the rate controlling species. Therefore an important reduction in process time would be expected. However, the diffusion coefficient of the MPD in the base material is just one factor contributing to the velocity of the process. Another important effect is the change of MPD solubility in the material. In an eutectic system the solubility normally decreases with increasing temperature. As a consequence, the factor $\mathrm{K}$ decreases and the velocity of solidification decreases. Also the fraction of MPD that has to be transported into the parent material to reach the solidus temperature of the braze increases. These effects result in an inverse temperature dependence, i.e. increasing the temperature does not necessarily shorten process time. Instead an optimum temperature exists where isothermal closure can be achieved in minimum process time. Similar findings are reported in the literature [16-19].

The reason for the change in the slopes of Figures 6 and 7 can also be attributed to a change in the factor K. As mentioned before, in the binary case $\mathrm{K}$ is a constant, depending on the different solubilities in the liquid and the solid phases. It is a function of the temperature rather than the time, as the solubilities only change with temperature. In a system with more components than two this can be different. If there is a change in the solubility during the process a change in $\mathrm{K}$ results and the velocity of the solid / liquid interface changes accordingly.

This change in the solubilites can occur as the system and the composition of the parent material at the interface constantly changes, due to interdiffusion of the regular constituents of the parent material into the liquid layer. This interdiffusion effect can be observed in the EPMA measurements presented in Figure 16 and 17, where a strong interdiffusion of aluminium, chromium and titanium can be found. The heavy elements, such as tungsten and rhenium have diffused, but to a lower extent. In case of René N5 (Figure 17), the amount of germanium in the initial gap area is higher, compared to the brazed sample of PWA 1483. This 
can be attributed to the lower diffusivity in second generation superalloys.

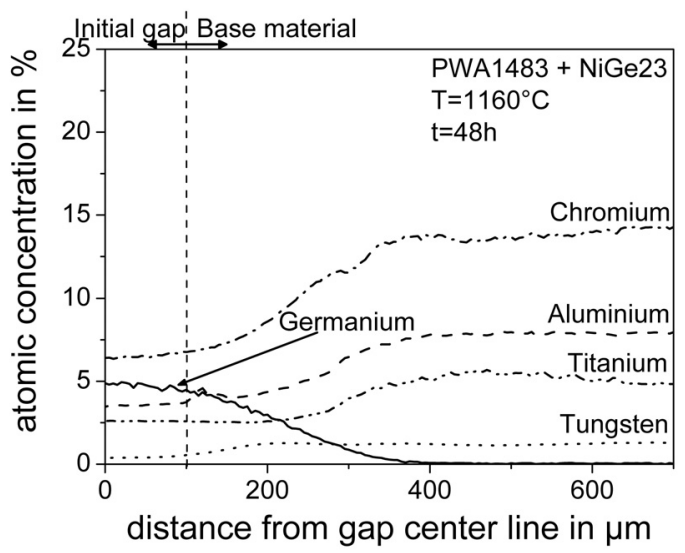

Figure 16: EPMA measurement of a PWA 1483 braze with NiGe23.

Another possible explanation for a solidification rate change with time is given by Ramirez et al. [19]. In their work a similar effect was found. The rate change was explained by a modification of the MPD concentration close to the solid / liquid interface. This changes the chemical composition gradient and therefore the driving force for diffusion of the MPD, in their case boron, decreases. From the experimental data accumulated in the presented work it can not clearly be decided if the change of MPD solubility, a local increase of MPD concentration at the solid / liquid interface or a combination of both effects is responsible for the solidification rate change.

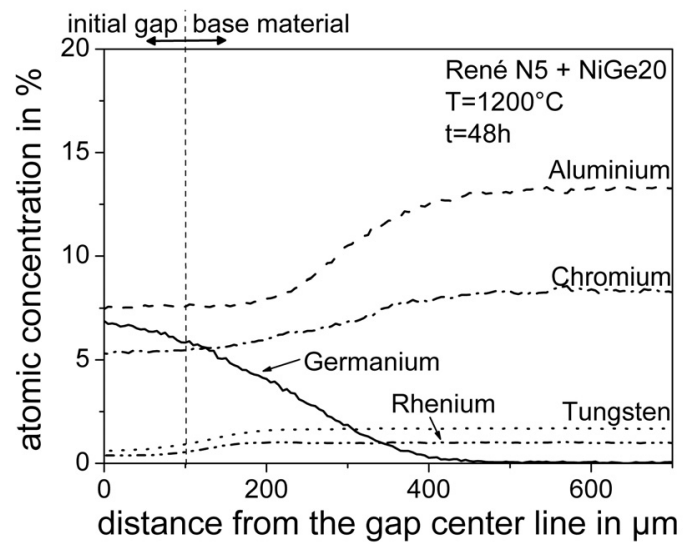

Figure 17: EPMA measurement of a René N5 braze with NiGe20

Due to the complexity of our system, at least 10 constituents for brazes of PWA 1483 and 13 constituents for René N5 brazes, it is not possible to see which effect dominates.

It is important to consider the solidification process in more detail. As mentioned previously, in the binary system the solidification is solely achieved by diffusion of the MPD into the base material. There is no driving force for a diffusion process in the opposite direction. In our system one has to take this diffusion of parent material alloying elements into account. One should mention that Nakao et al. [23] found good agreement with the binary theoretical model for the brazing of nickel-base superalloys with ternary Ni-Cr-B brazing alloys. They employed a small gap width, $50 \mu \mathrm{m}$. From Figures 6 and 7 it is obvious that the effect of a change in solidification velocity would not be encountered for gap widths below $150 \mu \mathrm{m}$. Therefore it seems that such effects are more pronounced at extended process times.

\section{Microstructure}

The microstructure in the joint area has shown a continuous transition from the base material to the joint center. No brittle phases were detected, but a change in size, shape and volume fraction of the $\gamma^{\prime}$-phase was found. The absence of any brittle phase could be explained by the lean composition of the braze alloys. Regarding the Ni-Al-Ge ternary phase diagram a continuous $\gamma / \gamma$-two phase region exists for Al-contents between about 75 to 90 at.\% and germanium contents between 78 to 90 at.\%. Germanium is a $\gamma^{\prime}$ - forming element and thus the interdiffusion of $\mathrm{Ge}$ into the base material should lead to an integration of the atoms into the already existing $\mathrm{Ni}_{3} \mathrm{Al}$ precipitates probably occupying Al-sites there. This is possible due to the complete miscibility of $\mathrm{Ni}_{3} \mathrm{Ge}$ and $\mathrm{Ni}_{3} \mathrm{Al}$ as reported by Ochiai et al. [26].

It seems that minor interdiffusion into the base material does not change the size and shape of the precipitates much, as found in the base material images in Figure 8 and 10. Here the microstructure is influenced by the high temperatures, close to the solution temperature, especially for PWA 1483, and extended dwell times. This leads to a partial solution of the $\gamma^{\prime}$-phase in the case of PWA 1483, where secondary $\gamma^{\prime}$-formation is observed, and an overall growth of the precipitations for both base materials.

Nevertheless, the lower melting point of $\mathrm{Ni}_{3} \mathrm{Ge}$ of about $1130{ }^{\circ} \mathrm{C}$ leads to a decrease of the solution temperature of the $\mathrm{Ni}_{3}(\mathrm{Al}, \mathrm{Ge})-$ phase which can be seen in the interdiffusion zone, where the precipitation microstructure appears fully solutionized and reprecipitated. Within this diffusion zone the concentration of the $\gamma^{\prime}$-forming elements is minimal, which leads to the minimum in the volume fraction, visible in Figure 9.

The size and shape of the precipitates in the diffusion zone and also in the joint center differs slightly between the two base materials.

\section{$\underline{\text { Mechanical Properties }}$}

The nanoindentation measurement for PWA 1483 with a NiGe23 braze alloy has resulted in Young's modulus values in the range of $225 \mathrm{GPa}$ to $240 \mathrm{GPa}$ which corresponds to literature results for nickel-base superalloys [27]. The decrease in the joint center can be attributed to the rather low content of alloying elements in the braze joint even after a fully completed brazing process, as can be seen in the EPMA measurements (Figure 14).

This also has a direct consequence on the hardness, which decreases roughly by $10 \%$. But as the solid solution strengthening elements such as tungsten diffused only slightly into the brazing area, this reduction in hardness seems to be reasonable. The high scatter might be a consequence of the microstructure of the brazing area. The regions of the highest scattering are located within the joint center, where the microstructure features very large $\gamma^{\prime}$ precipitates and a low volume fraction of the $\gamma$ phase. Due to the fact that the joint is mainly composed of nickel, germanium and a small amount of aluminum, these precipitations are probably of the type $\mathrm{Ni}_{3}(\mathrm{Ge}, \mathrm{Al})$, with a high content of 
germanium compared to aluminum. While $\mathrm{Ni}_{3} \mathrm{Ge}$ is also a $\mathrm{L}_{2}$ structured intermetallic phase, the mechanical properties of pure $\mathrm{Ni}_{3} \mathrm{Ge}$ are superior to pure $\mathrm{Ni}_{3} \mathrm{Al}$ [28]. The extraordinary strength of the $\mathrm{Ni}_{3} \mathrm{Al}$ based precipitates is a consequence of the alloying. It is also reported $[29,30]$ that $\mathrm{Ni}_{3} \mathrm{Ge}$ exhibits elastic moduli in the same range as $\mathrm{Ni}_{3} \mathrm{Al}$. This would explain the change of modulus observed in this work.

The nanoindentation measurements have shown a pronounced hardness decrease in René N5 of about $10 \%$ within the joint center. A smooth transition into the base material is found. Another point is that the brazing temperature in the case of PWA 1483 is closer to the solvus temperature of the $\gamma^{\prime}$ precipitates. Diffusion in the solid solution ought to be easier than in the two phase material, especially when the secondary phase is intermetallic, as diffusion in intermetallics is slower [31]. An analogous difference in strength can be seen in the hot tensile tests, PWA 1483 brazes achieve a higher strength level compared to the reference sample than René N5. In the case of PWA 1483 with $\mathrm{NiGe} 23$ a maximum value of about $97 \%$ is reached, whereas for René N5 with NiGe20 a maximum value of $92 \%$ of the strength of the reference material was obtained. Compared with values for standard heat treated samples this would lead to strength levels achieved for brazings of $82 \%$ for PWA 1483 and $78 \%$ for René N5. But considering the microstructure an enhancement of these results by an additional heat treatment seems possible.

The effect of the change from conventional to isothermal solidification of a braze material can be observed in Figure 14. The strength of the $24 \mathrm{~h}$ sample represents the result of a prematurely aborted heat treatment. In this case no isothermal gap closure was achieved and the strength reaches just about $40 \%$ of the reference material value. Once the gap closure is finished the strength of the joint strongly increases to values of about $80 \%$ of the reference material value. The main reason for this is the elimination of grain boundaries perpendicular to the stress axis. Fractographic images which are not presented here indicated that in the $24 \mathrm{~h}$ samples some residual melt was present. Also the inferior strength in the $24 \mathrm{~h}$ sample could be attributed to effects like solidification porosity, because the final gap closure is achieved by conventional dendritic solidification. This can lead to a cut off from additional feed. A challenge in braze alloy development is normally the ductility of the joints. Conventional brazes tend to have rather inferior ductility compared to the base/parent material. The stress strain curves presented in Figure 14 show rupture strains of about $2 \%$ for the brazed samples. Compared to the $20 \%$ base material rupture strain this seems rather disappointing, in particular when the very promising microstructures are taken into account. However, one has to consider the somewhat lower strength of the bond area and the ensuing strain concentration. As already mentioned before the extensometer used has a gauge length of $12 \mathrm{~mm}$ which was the basis of the calculation of the 20 or $2 \%$ strain to failure, resp. The most affected joint area that displays a decrease in strength is about $800 \mu \mathrm{m}$ for PWA 1483 with NiGe23 and $400 \mu \mathrm{m}$ for René N5 with NiGe20. If we shall assume that most deformation takes place in this limited "gauge length", we calculate approximately $30 \%$ rupture strain in the PWA 1483 samples. For René N5 the same calculation would lead to a rupture strain values of 20 to $25 \%$.
Nishimoto et al. [3] have reported strengths of their SX joints that are actually higher than the parent material strength, which was CMSX-2. These joints have been achieved with a ternary Ni-Cr-B braze alloy. Nevertheless, these values are achieved with gaps of $40 \mu \mathrm{m}$ width. Also their joints exhibit a decrease in elongation to failure compared to the reference samples.

Ojo et al. [22] on the other hand have reported inferior joint strengths for their brazings of the polycrystalline Inconel 738. In this study two different braze alloys were compared, a quaternary braze alloy and a braze alloy with 6 components. The 6 component braze reached strengths of close to $90 \%$ reference strength. But it was also shown that for the 4 component braze alloy, the joint strength decreased with increasing joint width.

\section{Summary}

- Germanium was identified as a new melting point depressing element for Transient Liquid Phase Bonding of single crystalline nickel-base superalloys. It was applied successfully to achieve SX joints in two different SX base materials, PWA 1483 and René N5.

- Within the joint region no brittle phases were detected.

- A $\gamma / \gamma^{\prime}$ microstructure was achieved, consisting partially of $\mathrm{Ni}_{3} \mathrm{Ge}$ based precipitates and the nickel solid solution matrix.

- During the brazing process an interdiffusion of the melting point depressing element to the parent material as well as of the regular superalloy constituents into the joint region took place.

- Solidification kinetics were two staged for most observed process temperatures, due to the complexity of the solidification and interdiffusion mechanisms in these multicomponent systems.

- Nanoindentation results at room temperature revealed small differences in modulus and hardness for both base material brazings. Variations were more pronounced for René N5.

- Hot tensile tests have shown promising mechanical properties with strengths of the joint in the order of $95 \%$ for the PWA 1483 joints and $92 \%$ for the René N5 joints, compared to reference samples with simulated brazing cycles.

\section{Acknowledgements}

This work was performed within the KW21 program. The authors would like to thank the Bavarian Research Foundation and the Bavarian State Ministry of Sciences, Research and the Arts for financial grants.

\section{References}

T. J. Carter, "Common failures in gas turbine blades," Engineering Failure Analysis, 2005. 12, 237-247.

[2] Y. Zheng, L. Zhao, and K. Tangri, "Microstructure of $\mathrm{Ni}-10 \mathrm{Co}-8 \mathrm{Cr}-4 \mathrm{~W}-13 \mathrm{Zr}$ alloy and its bonding behaviour for single-crystal nickel-base superalloy, ” Journal of Materials Science, 1993. 28, 823-829. 
[3] K. Nishimoto et al., "Transient Liquid Phase Bonding of Ni-base Single Crystal Super-alloy. CMSX-2," ISIJ International, 1995. 35(10), 1298-1306.

[4] R. Zhongci, W. Shuncai, and Z. Yunrong, "Microstructure and bonding behaviour of a new Hfbearing interlayer alloy for single crystal nickel-base superalloy," Scripta Mat., 1996. 34(1), 163-168.

[5] K. Nishimoto et al., "Bonding phenomena and joint properties of transient liquid phase bonding of Ni-base single crystal superalloys, "Welding World, 1998. 41, 121-131.

[6] D. Kim and K. Nishimoto, "Bonding Phenomena of transient liquid phase bonded joints of a Ni base single Crystal superalloy," Metals and Materials International, 2002. 8(4), 403-410.

[7] A. Schnell, "A Study of the diffusion brazing process applied to the single crystal superalloy CMSX-4," $\mathrm{PhD}$ Thesis, Ecole Polytechnique Fédérale de Lausanne, 2004.

[8] D.S. Duvall, W.A. Owczarski and D.F. Paulonis, "TLP Bonding: A new Method for Joining Heat Resistant Alloys, ” Welding Journal, 53, 1974, 203-214

[9] S.K. Tung, L.C. Lim and M.O. Lai, "Solidification Phenomena in Nickel-base Brazes containing Boron and Silicon," Scripta Mat. 34, 1, 1996, 763-769

[10] T.B. Massalski, Binary Alloy Phase Diagrams, Second Edition, (Metals Park, OH: ASM International), 1990

[11] A.J. Wilkinson and P.B. Hirsch, "Electron Diffraction Based Techniques in Scanning Electron Microscopy of Bulk Materials, " Micron, 28, 4, 1997, 279-308

[12] W.C. Oliver and G.M. Pharr, "An Improved Technique for Determining Hardness and Elastic Modulus using Load and Displacement Sensing Indentation Experiments," J. Mater. Res. 7, 1992, 1564-1583

[13] K. Durst and M. Göken, "Micromechanical characterisation of the influence of rhenium on the mechanical properties in nickel-base superalloys, " Mat. Sci. Eng. A 387-389, 2004, 312-316

[14] M. Göken and M. Kempf, "Microstructural properties of superalloys investigated by nanoindentations in an atomic force microscope," Acta Mat. 47, 3, 1999, 1043 1052

[15] M. Nazmy et al., "Environmental effects on tensile and low cycle fatigue behavior of single crystal nickel-base superalloys," Scripta Mat. 48(5), 2003, 519-524.

[16] G. Lesoult, "Modelling of the transient liquid phase bonding process, ” CJM Report, 1976.

[17] I. Tuah-Poku, M. Dollar and T.B. Massalski, “A study of the Transient Liquid Phase Bonding Process Apploed to a Ag/Cu/Ag Sandwich Joint," Metall. Trans. A. Vol 19A, 1988, 675-686

[18] W.D. MacDonald and T.W. Eagar, "Transient liquid phase bonding, ” Annual Rev. Materials Science, 22, 1992, 23-46.
[19] J.E. Ramirez and S. Liu, "Diffusion Brazing in the Nickel-Boron System," Welding Research. October, 1992, 365-375

[20] N.P. Wikstrom, O.A. Ojo and M.C. Chaturvedi, "Influence of process parameters on microstructure of transient liquid phase bonded Inconel 738LC superalloy with Amdry DF-3 interlayer," Mat. Sci. Eng. A 417, 12, 2006, 299-306

[21] O.A. Idowu, N.L. Richards and M.C. Chaturvedi, "Effect of bonding temperature on isothermal solidification rate during transient liquid phase bonding of Inconel 738LC superalloy,” Mat. Sci. Eng. A 397, 2005, 98-112

[22] O.A. Ojo, N.L. Richards and M.C. Chaturvedi, "Effect of gap size and process parameters on diffusion brazing of Inconel 738," Science and Technology of Welding and Joining, 9, No. 3, 2004, 209-220

[23] Y. Nakao et al. "Theoretical research on transient liquid insert metal diffusion bonding of nickel-base alloys, " In: Proceedings Superalloys 1988, edited by S. Reichman, D.N. Duhl, G. Maurer, S. Antolovich and C. Lund, (Warrendale, PA: TMS Superalloys, 1988) 775783 ,

[24] C.W. Sinclair, "Modeling Transient Liquid Phase Bonding in Multicomponent Systems," J. Phase Equilibria, 20, No. 4, 1999, 361-369

[25] C.W. Sinclair, G.R. Prudy, and J.E. Morral, "Transient liquide phase bonding in two-phase ternary systems," Metal. Mat. Transactions A, 31, 2000, 1187-1192.

[26] S. Ochiai, Y. Oya, and T. Suzuki, “Alloying Behaviour of $\mathrm{Ni}_{3} \mathrm{Al}, \mathrm{Ni}_{3} \mathrm{Ga}, \mathrm{Ni}_{3} \mathrm{Si}$ and $\mathrm{Ni}_{3} \mathrm{Ge}$," Acta Metall., 32, 2 , 1984, 289-298

[27] K. Durst, O. Franke and M. Göken, "Nanoindentations as a local Probe for the mechanical properties and alloying influences in Nickel-base superalloys and aluminide coatings," In: Proceedings Superalloys 2004,edited by: K.A. Green, T.M. Pollock, H. Harada, T.E. Howson, R.C. Reed, J.J. Schirra, and S. Walston, (Warrendale, PA: TMS Superalloys 2004), 467-476

[28] T. Suzuki, Y. Mishima and S. Miura, "Evaluation of the data for the plastic behaviour of Ni3(Al,X) single crystals,” Mat. Sci. Eng. A, 146, 1991, 245-260

[29] K. Tanaka and M. Koiwa, "Single-crystal elastic constants of intermetallic compounds, " Intermetallics 4, 1996, 29-39

[30] S.Y. Prikhodko et al., "The elastic constants of FCC NiGa and Ni-Ge alloys up to $1100 \mathrm{~K}$," Scripta Mat., 54, 2006, 1327-1330

[31] C. Cserháti et al., "Tracer diffusion of ${ }^{63} \mathrm{Ni}$ in $\mathrm{Ni}_{3}(\mathrm{Al}, \mathrm{Ge})$ ternary intermetallic compound," Intermetallics, 10, 2002, 887-892 